\title{
Design of Ellipse Antenna Array for Cellular Phone Localization Systems
}

\author{
Ahmad El Sayed Ahmad ${ }^{*}{ }^{\circledR}$, Jean-Marie Floc'h2 ${ }^{2}$, Alaa Choumane ${ }^{3} \mathbb{C}^{\circ}$, Philippe Morgand $^{4}$ \\ ${ }^{1}$ Faculty of Sciences, Lebanese University, Tripoli, Lebanon \\ ${ }^{2}$ IETR, INSA Rennes, Rennes, France \\ ${ }^{3}$ Faculty of Public Health, Lebanese University, Zahle, Lebanon \\ ${ }^{4}$ Thales Communication, Colombes, France \\ Email: *elsayed.ahmad84@gmail.com, Jean-Marie.Floch@insa-rennes.fr, alaa.choumane@ul.edu.lb, phmorgand@gmail.com
}

How to cite this paper: El Sayed Ahmad, A., Floc'h, J.-M., Choumane, A. and Morgand, P. (2020) Design of Ellipse Antenna Array for Cellular Phone Localization Systems. Wireless Engineering and Technolo$g y, 11,13-22$.

https://doi.org/10.4236/wet.2020.112002

Received: April 1, 2020

Accepted: April 27, 2020

Published: April 30, 2020

Copyright $\odot 2020$ by author(s) and Scientific Research Publishing Inc. This work is licensed under the Creative Commons Attribution International License (CC BY 4.0).

http://creativecommons.org/licenses/by/4.0/

\begin{abstract}
This paper describes our contribution in the ANR (Agence Nationale de la Recherche) project called GELOCOM (GEo-LOCalisation de telephOnes Mobiles) managed by the THALES Communications company, dedicated to the emergency localization of cellular phones. This contribution takes place in the field of antennas, with the development of broad-band systems: a circular array of six elements with separated outputs for the receiving part. In this paper, we present the design and the characterization of broad-band double ellipse array antenna. This special structure is chosen in order to obtain a good omnidirectional radiation pattern, enhance the gain and maximize the $\mathrm{V} / \mathrm{H}$ polarization ratio. In comparison with the already existing antenna systems in the wireless market for similar purposes, the proposed antenna has considerably shown better performance which makes it competitive among other antenna models. For the design and optimization of antennas, we use CST MWS software. The antennas have been designed and successfully measured.
\end{abstract}

\section{Keywords}

Broad-band Antenna, Double Ellipse Antenna, Planar Monopole Antenna, Elliptical Antenna, Omnidirectional Radiation Pattern

\section{Introduction}

This paper describes the design and development of antennas able to cover a wide frequency bandwidth for use in detection system placed on the roof in vehicle. The project GELOCOM is part of the surveillance of risk areas or after a disaster by detection and localization by means of mobile communications in the range $500 \mathrm{MHz}$ to $2 \mathrm{GHz}$. This electrical activity monitoring radio is intended to be used for search and rescue but also for the monitoring of individuals under 
the protection of citizens against terrorism and crime (big or small crime) or for the monitoring of borders or risk area covering an area of passage of people. Moreover no particular equipment is needed for GSM, DCS and UMTS owners; they only have to put their cellular on wait mode. To achieve this detection, one antenna systems is needed, both covering the GSM, DCS and UMTS bands, while presenting good mechanical characteristics.

Monopole antennas have several advantages but they have a narrow bandwidth. Broad-band planar monopole antennas have all the advantages of the monopole in terms of their cost, and ease of fabrication besides, yielding very large bandwidths. For many applications large bandwidth is required. The radiation performance is also shown to be acceptable over a wide range of frequency. Investigations on planar monopoles of different geometrical shapes, such as the circular, triangular, rectangular and elliptical have since been conducted [1] [2].

A planar monopole may be realized by replacing the wire element of a conventional monopole with a planar element. The planar element is located at a distance above the ground plane [3]. The replacing of wire element with planar element, with various shapes, increases the surface areas of the monopoles, thereby having a direct impact on bandwidth. Planar monopole antennas have long been used in mobile communications. Several planar monopoles such as circular, elliptical, square, rectangular, hexagonal and pentagonal, have been analyzed, providing wide impedance bandwidth. Among all these configurations, the circular monopole [4] [5] and the elliptical monopole fed along the major axis were reported to yield maximum bandwidth [6]. More recently, it has been shown that, although the square monopole provides smaller bandwidth than the circular monopole, its radiation pattern suffers less degradation within the impedance bandwidth [6]. Planar monopole antennas can be optimized to provide extremely wide impedance bandwidth with acceptable radiation performance. Also in reconfigurable radio systems, planar monopole antennas provide maximum flexibility by radiating over radio terminal's entire frequency range [7].

Until now, the achieved impedance bandwidth for VSWR $=2: 1$ have usually reached about 10:1 for an elliptical planar monopole and 80\% for the other planar monopoles. So, we have chosen the elliptical monopole antenna. In the other hand, the elliptical monopole radiation pattern suffers more degradation within the impedance bandwidth. To solve this problem, we have synthesized a special double-ellipse antenna. Very good results were obtained in terms of $S_{11}$, polarization ratio $(\mathrm{V} / \mathrm{H})$ and realized Gain.

This paper is organized as follows: first, we present the system principle. In section 3, a design concept of the proposed double ellipse antenna is described. Finally, the array of six double-ellipses antenna is simulated, realized, and characterized by measuring her return loss, radiation patterns, and gain.

\section{System Principle}

The location will be conducted in indoor using the two goniometry stations, ar- 
ranged in outdoor and delivering the angular information of arrival directions of radio-electric sources considered. The information from the two previous stations will be merged in order to estimate the position in three dimensions $\mathrm{X}, \mathrm{Y}$, $\mathrm{Z}$ of transmission sources.

Six antennas are needed to operate a good goniometry of the uplink signal. Moreover, this antenna has to form a circular array with separated outputs. Phase and magnitude of the received signal on each antenna are then analyzed with a MUSIC-type algorithm to calculate the DOA (direction of arrival). The MUSIC algorithm (MUltiple SIgnal Classification) is a high-resolution direction-finding algorithm based on the eigenvalue decomposition of the sensor covariance matrix observed at an array. MUSIC belongs to the family of subspace-based direction-finding algorithms.

\section{Antenna Design}

\subsection{Basic Antenna Element}

In the terms of performances, the antenna must be omnidirectionnal and generate a polarization with ratio $\mathrm{V} \backslash \mathrm{H}$ upper than $16 \mathrm{~dB}$ over an angular aperture of $\theta$ $=60^{\circ}\left\{\left[30^{\circ}, 90^{\circ}\right]\right.$ and $\left.\left[-30^{\circ},-90^{\circ}\right]\right\}$. The boresight direction is $\theta$ equals to $0^{\circ}$. Concerning the gain, it must be higher than $0 \mathrm{~dB}$ over the desired angular aperture. The reflection coefficient must be less than $-6 \mathrm{~dB}$ over the all bands (GSM, DSC and UMTS). At first, we studied a simple planar elliptical monopole antenna, we obtained good performance $\left(\mathrm{S}_{11}\right.$, Gain), against the $\mathrm{V} / \mathrm{H}$ polarization ratio was not good, and the radiation pattern was not symmetrical. For optimize the specifications antenna, we have developed a special double-ellipse antenna. Very good results were obtained ( $\mathrm{S}_{11}$, polarization, Gain).

The dimensions of the double-ellipse are presented in Figure 1. The length of major diameter is $10 \mathrm{~cm}$. The minor diameter length is $60 \%$ of the major diameter length. The distance between the antenna and the ground plane is equal to 2 $\mathrm{mm}$.

The simulated reflection coefficient evaluation is shown in Figure 2. The antenna matching level is lower than $-6 \mathrm{~dB}$ from $500 \mathrm{MHz}$ to $4 \mathrm{GHz}$.

Figure 3 presents the radiation pattern in $3 \mathrm{D}$ at four frequencies $(400 \mathrm{MHz}$, $890 \mathrm{MHz}, 1710 \mathrm{MHz}$, and $2000 \mathrm{MHz}$ ). The 3D radiation pattern simulation shows a very omnidirectional lobe.

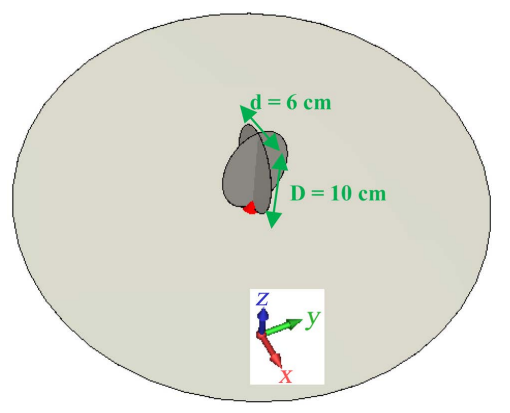

Figure 1. The proposed antenna. 


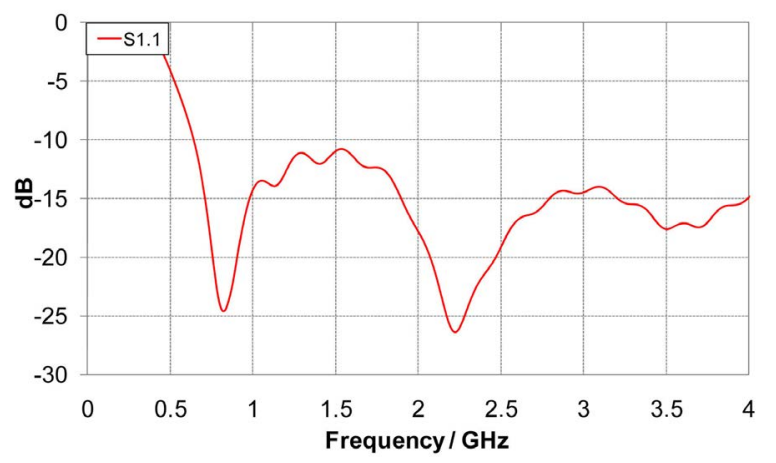

Figure 2. Simulated $S_{11}$.
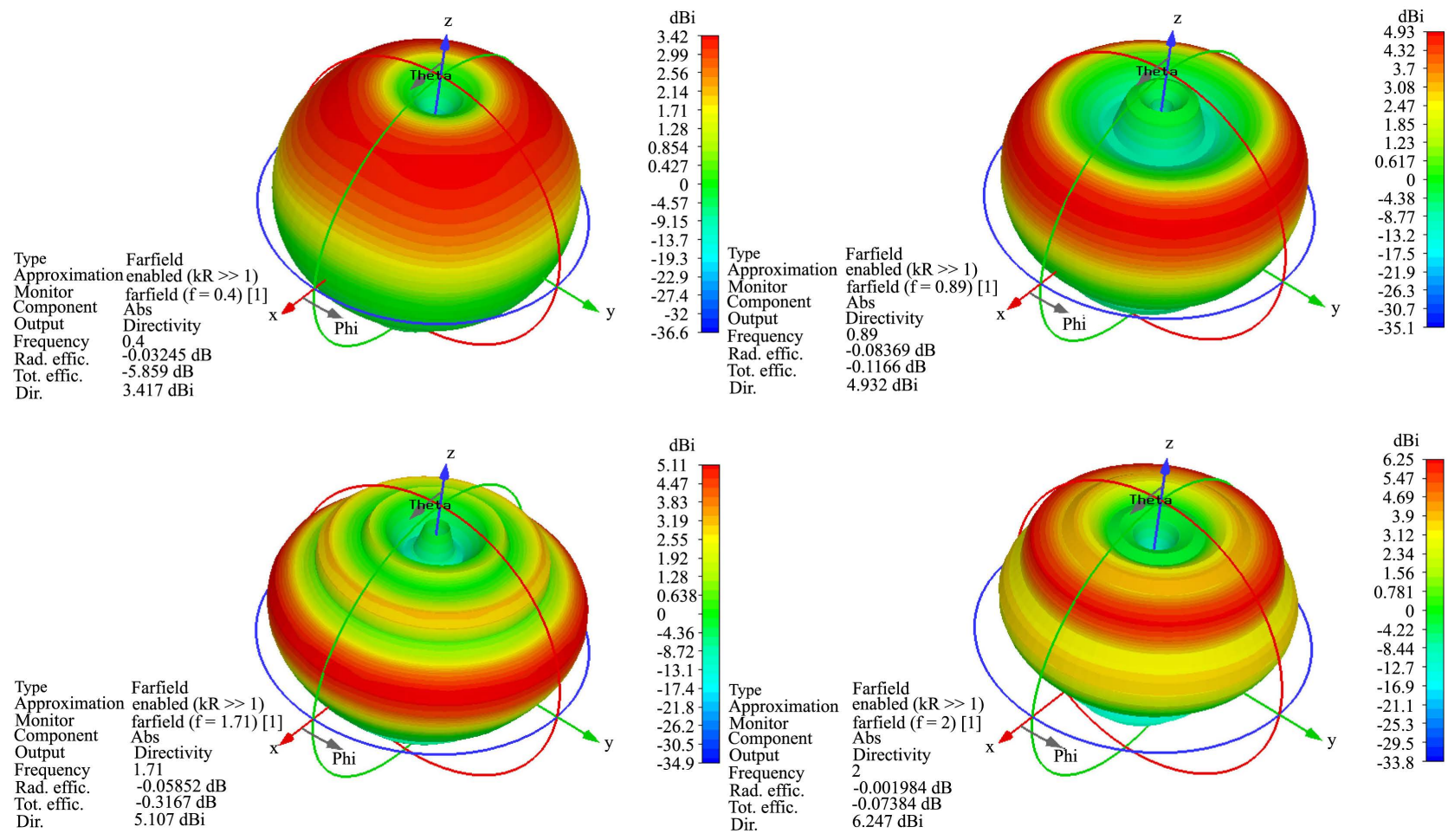

Figure 3. The 3D simulation radiation pattern of the antenna at four frequencies.

\subsection{Double-Ellipse Array Antenna (Simulations)}

Considering the good performances of this basic element, six double-ellipses have been developed to achieve a good goniometry of the uplink signal. Moreover, five elements form a circular array and one element insert in the center with separated outputs (to obtain better performances). Due to the broad-band working of this array, an optimal distance between the elements has to be found to offer the best compromise relatively to the different wavelengths (diameter $=$ $60 \mathrm{~cm}$ ). The prototype must be made on a circular ground plane whose diameter is $\Phi=120 \mathrm{~cm}$. The array of antennas is shown on Figure 4 .

The array of antennas was studied with the software CST MWS. The $S_{\mathrm{ii}}$ depicted in Figure 5 shows that a value better than $-6 \mathrm{~dB}$ is obtained for all the bands. We note that the antennas 2, 3, 4, 5 and 6 are symmetrical with respect to 


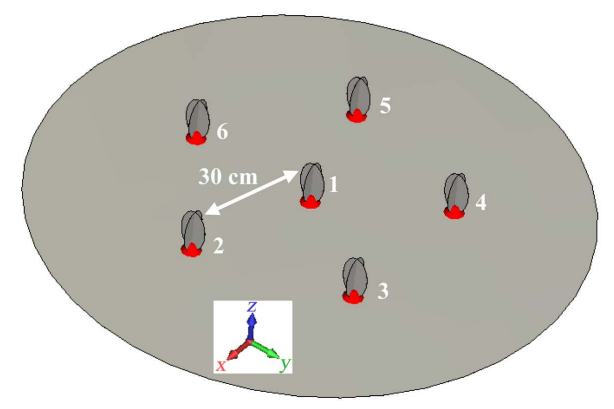

Figure 4. Array of antennas.

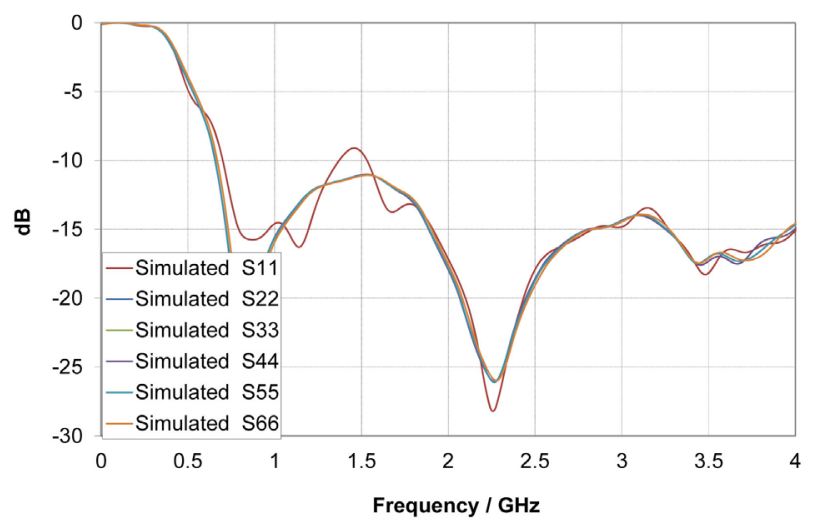

Figure 5. Simulated $S_{\text {ii. }}$

the ground plane and to the antenna 1 which is in the center. For this reason, they have the same reflection coefficient $\left(S_{22}=S_{33}=S_{44}=S_{55}=S_{66}\right)$. Figure 6 shows that the couplings between elements could reach $-15 \mathrm{~dB}$ in the worst cases. The simulated radiation pattern is plotted on the Figure 7. The radiation pattern is successfully synthesized. The results are slightly below our expectations at angle $\theta$ higher than $80^{\circ}$. This finds an explanation in the finite ground plane whose diameter is $120 \mathrm{~cm}$. Figure 8 illustrates the simulated $\mathrm{V} / \mathrm{H}$ polarization ratio over the angular theta at 960,1800 and $2000 \mathrm{MHz}$. It can notice the $\mathrm{V} / \mathrm{H}$ upper than $16 \mathrm{~dB}$ over the angular aperture: $\left[30^{\circ}<\theta<90^{\circ}\right]$ and $\left[-30^{\circ}<\theta<\right.$ $\left.-90^{\circ}\right]$.

\subsection{Double-Ellipse Array Antenna (Measurements)}

The antenna was manufactured as can be seen in Figure 9 and Figure 10 (with radome). The measurements were achieved in the laboratory anechoic chamber between $500 \mathrm{MHz}$ and $2000 \mathrm{MHz}$ and have been compared with simulation. The antenna return loss depicted in Figure 11 shows that values better than $-6 \mathrm{~dB}$ are obtained on $\left|S_{11}\right|$.

We present the measured realized gain at 960, 1800 and $2000 \mathrm{MHz}$ (Figure 12). We note a good comparison between simulation and measurement. The difference between the simulated realized gain and the measured realized gain is around $1 \mathrm{~dB}$. The measurement accuracy of the anechoic chamber $( \pm 1 \mathrm{~dB})$ can be responsible for this variation. 


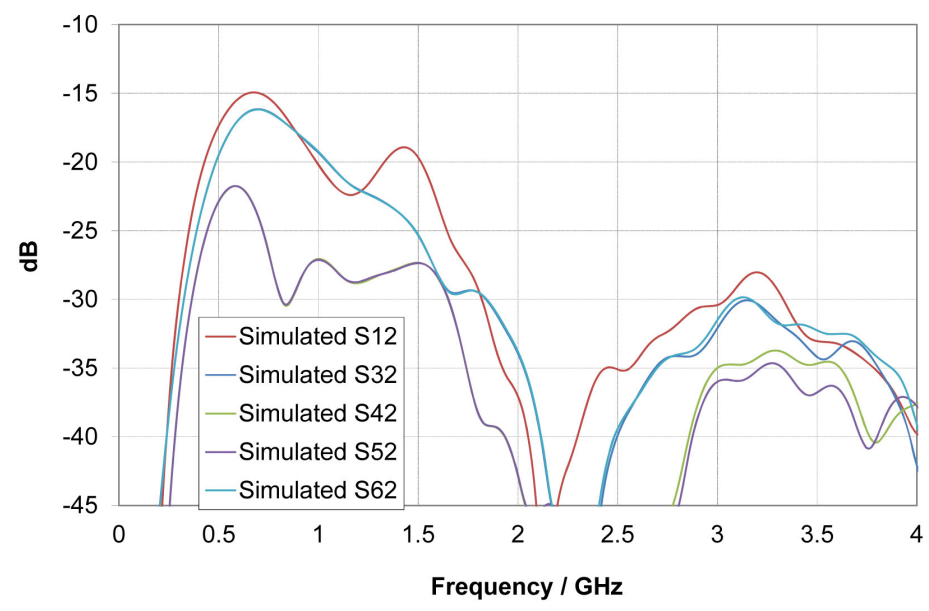

Figure 6. Simulated $S_{\mathrm{ij} .}$
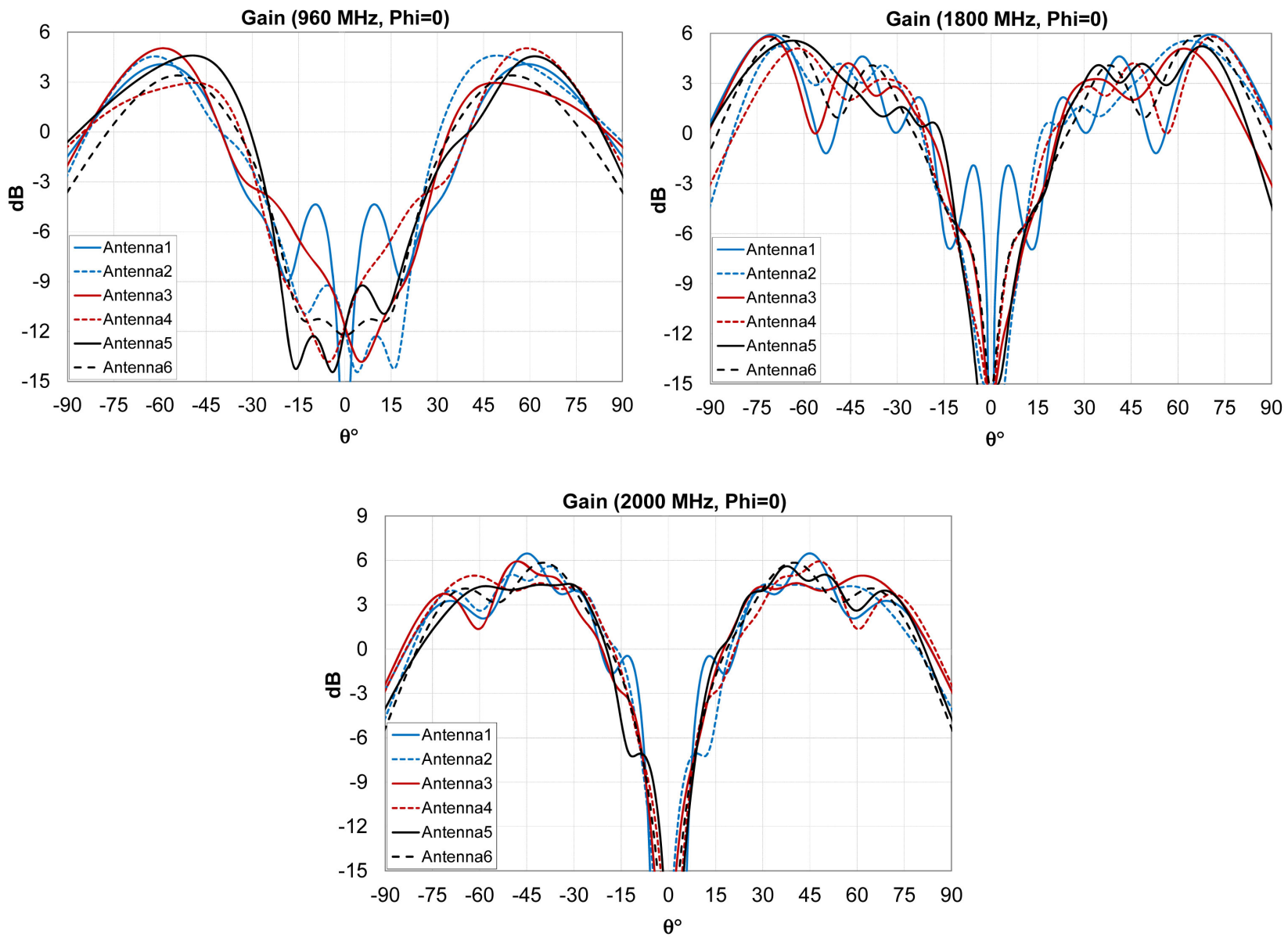

Figure 7. Simulated radiation results at 960, 1800 and $2000 \mathrm{MHz}$.

Figure 13 shows the measured $\mathrm{V} / \mathrm{H}$ polarization ratio over the angular theta at 960,1800 and $2000 \mathrm{MHz}$. The measured $\mathrm{V} / \mathrm{H}$ ratio is still upper than $16 \mathrm{~dB}$ over the angular aperture: $\left[30^{\circ}<\theta<90^{\circ}\right]$ and $\left[-30^{\circ}<\theta<-90^{\circ}\right]$, except for the case corresponding to the result obtained at $\mathrm{f}=960 \mathrm{MHz}$ for angle $\theta$ between $-30^{\circ}$ and $-60^{\circ}$ (Antenna 4 ). 

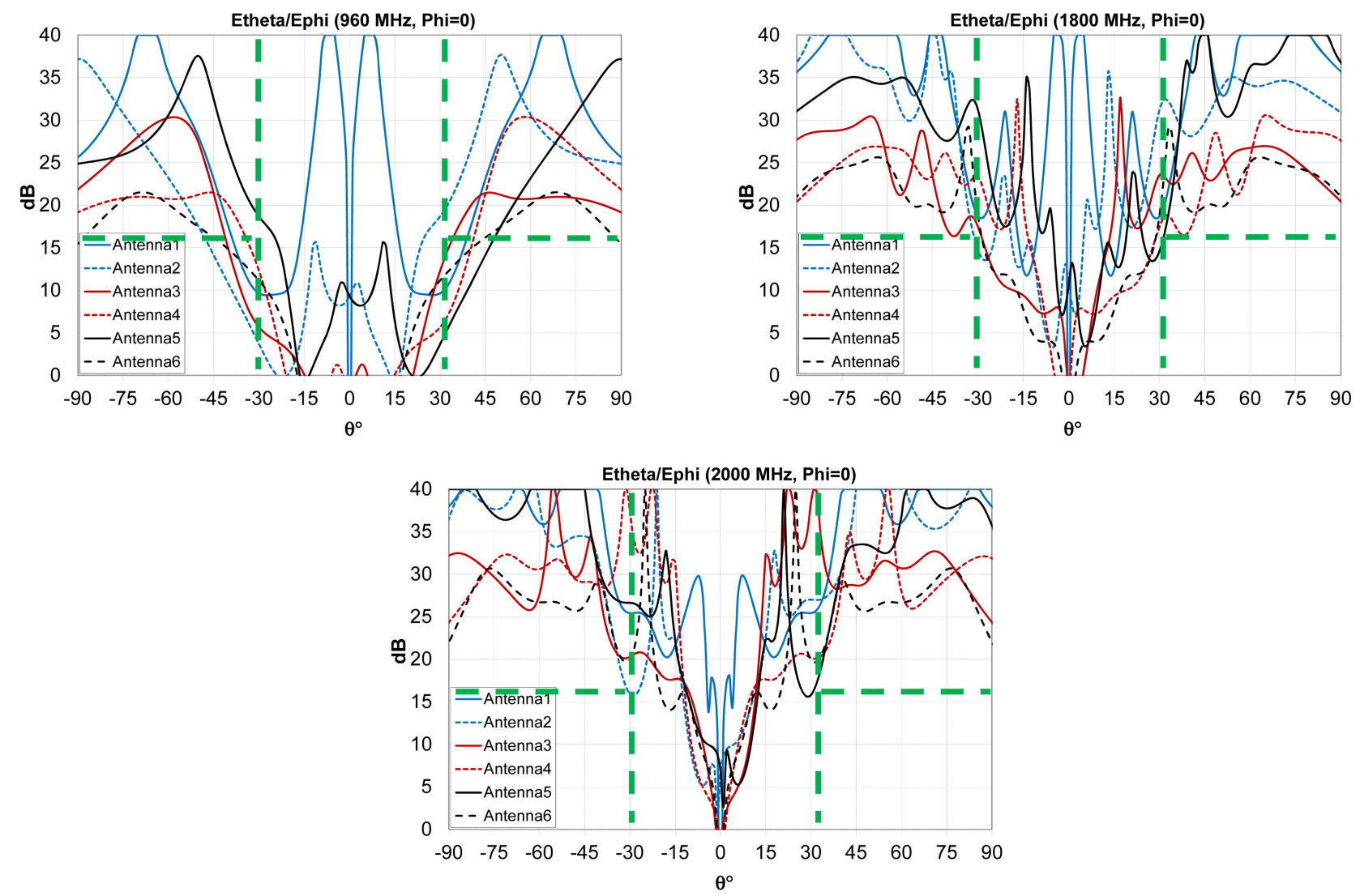

Figure 8. Simulated polarisation results at 960, 1800 and $2000 \mathrm{MHz}$.

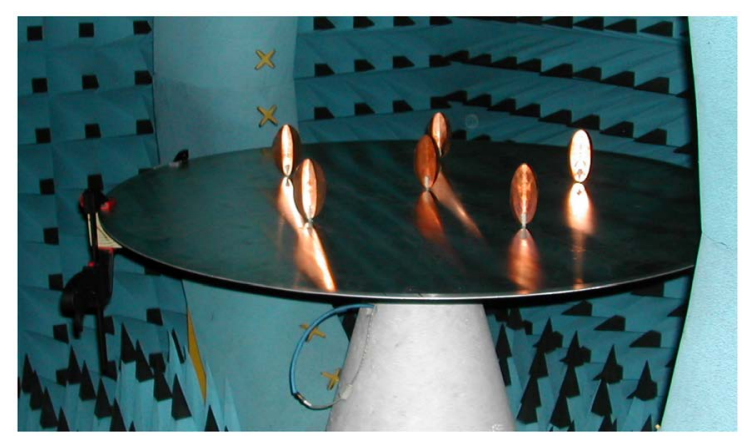

Figure 9. Achieved prototype in anechoic chamber.

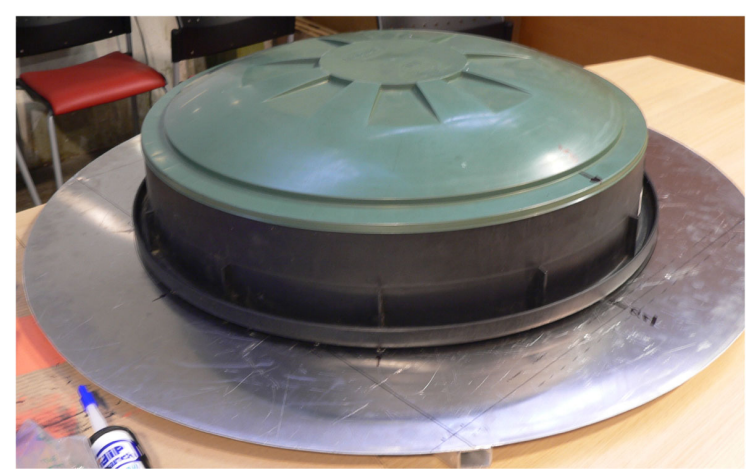

Figure 10. Achieved prototype with radome. 


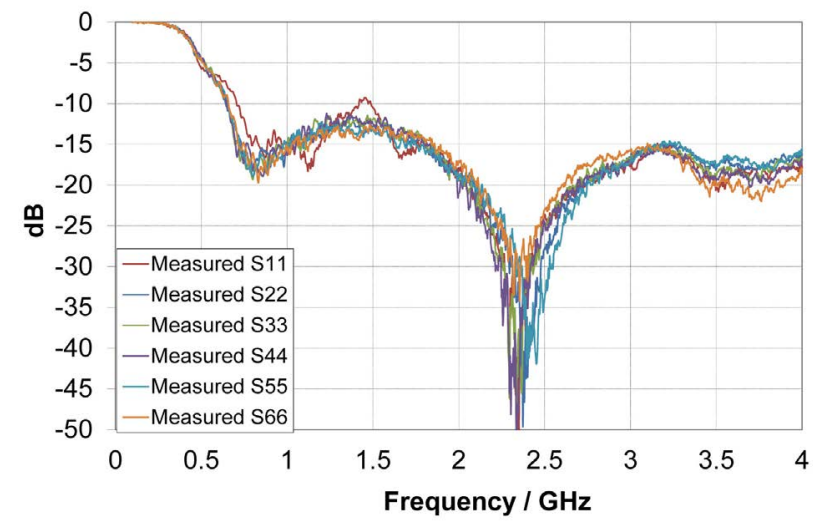

Figure 11. Measured return loss.
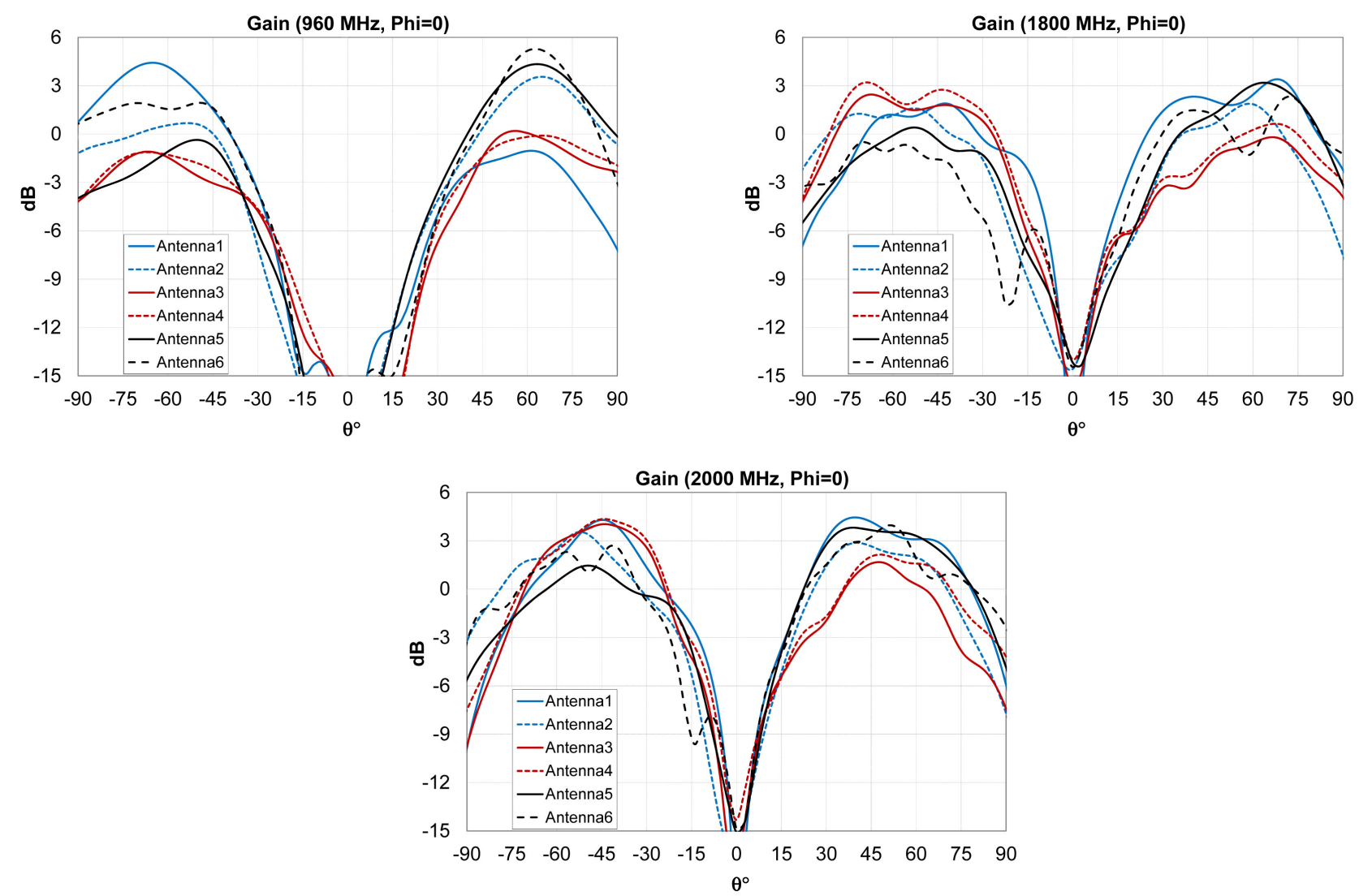

Figure 12. Measured radiation results at 960, 1800 and $2000 \mathrm{MHz}$.

\section{Conclusion}

In this paper, a special broad-band double-ellipse array antenna was presented. At first, we studied a simple planar elliptical monopole antenna, we obtained good performance $\left(S_{11}\right.$, Gain), against the $\mathrm{V} / \mathrm{H}$ polarization ratio was not good, and the radiation pattern was not symmetrical. After various parametric studies the optimum design was obtained. Very good results were obtained $\left(S_{11}\right.$, polarization, Gain). In the terms of performances, the antenna radiates an omnidirectionnal lobe and generates a polarization with ratio $\mathrm{V} \backslash \mathrm{H}$ upper than $16 \mathrm{~dB}$ over 

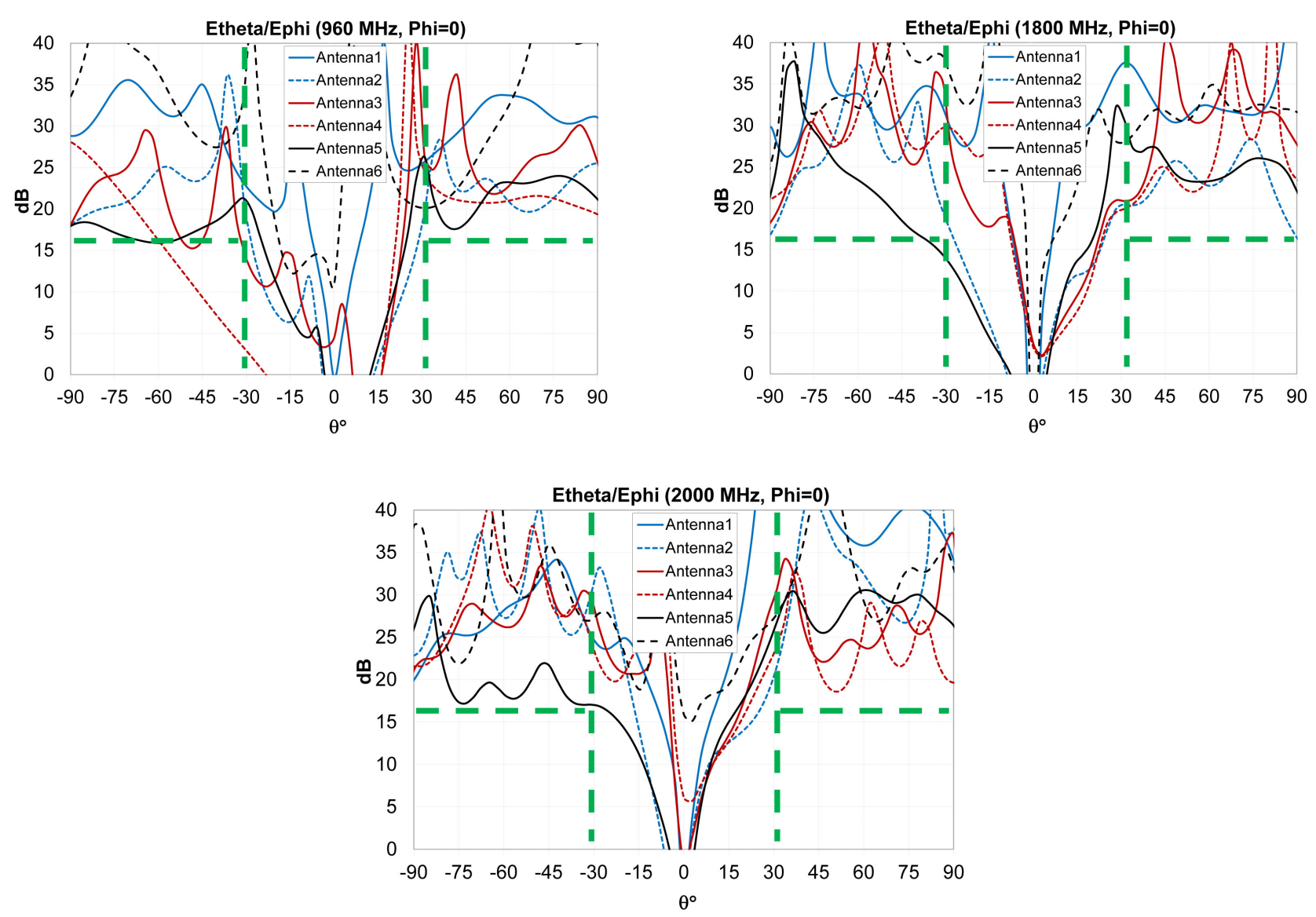

Figure 13. Measured polarization results at 960, 1800 and $2000 \mathrm{MHz}$.

an angular aperture of $\theta=60^{\circ}\left\{\left[30^{\circ}, 90^{\circ}\right]\right.$ and $\left.\left[-30^{\circ},-90^{\circ}\right]\right\}$. Concerning the gain, it is higher than $0 \mathrm{~dB}$ over the desired angular aperture. The reflection coefficient is less than $-6 \mathrm{~dB}$ over the all bands (GSM, DSC and UMTS). We note very good results in terms of reflection coefficient, gain and polarization and we obtain good comparison between simulations and measurements. This antenna is very suitable for cellular phone localization systems.

\section{Conflicts of Interest}

The authors declare no conflicts of interest regarding the publication of this paper.

\section{References}

[1] Agarwall, N.P., Kumar, G. and Ray, K.P. (1998) Wide-Band Planar Monopole Antennas. IEEE Transactions on Antennas and Propagation, 46, 294-295. https://doi.org/10.1109/8.660976

[2] Ray, K.P., Anob, P.V., Kapur, R. and Kumar, G. (2001) Broadband Planar Rectangular Monopole Antennas. Microwave Optical Technology Letters, 28, 55-59. https://doi.org/10.1002/1098-2760(20010105)28:1<55::AID-MOP16>3.0.CO;2-X

[3] Lee, E., Hall, P.S. and Gardner, P. (1999) Compact Wideband Planar Monopole Antenna. Electronics Letters, 35, 2157-2159. https://doi.org/10.1049/el:19991491 
[4] Kumar, G. and Ray, K.P. (2002) Broadband Microstrip Antennas. Artech House, United States.

[5] Honda, S., Ito, M., Seki, H. and Jingo, Y. (1992) A Disc Monopole Antenna with 1:8 Impedance Bandwidth and Omnidirectional Radiation Pattern. Proceedings of theInternational Symposium on Antennas and Propagation (ISAP) Conference, Sapporo, 22-25 September 1992, 1145-1148.

[6] Hammoud, Poey, P. and Colomel, F. (1993) Matching the Input Impedance of a Broadband Disc Monopole. Electronics Letters, 29, 406-407. https://doi.org/10.1049/el:19930272

[7] Ammann, M.J. and Zhi, N.C. (2003) Wideband Monopole Antennas for Multi-Band Wireless Systems. IEEE Antennas and Propagation Magazine, 45, 146-150. https://doi.org/10.1109/MAP.2003.1203133 